\title{
Modulation of hormone secretion by functional electrical stimulation of the intact and incompletely dysfunctional dog pancreas
}

J. Rozman ${ }^{1}$,
M. Bunc ${ }^{2}$ and
B. Zorko ${ }^{3}$
${ }^{1}$ ITIS d.o.o. Ljubljana, Center for Implantable Technology and Sensors,

${ }^{2}$ School of Medicine, Institute of Pathophysiology, and

${ }^{3}$ Veterinary Faculty, University of Ljubljana, Ljubljana, Republic of Slovenia
Correspondence

J. Rozman

ITIS d.o.o. Ljubljana

Lepi pot 11

1000 Ljubljana

Republic of Slovenia

Fax: +38-6-1470-1939

E-mail: janez.rozman@guest.arnes.si

Research supported by the Ministry of Education, Science and Sport, Ljubljana, Republic of Slovenia (No. J2-3415) and HPRN-CT-

2000-00030 from the European

Commission.

Received March 11, 2003 Accepted November 18, 2003 ...........................

\begin{abstract}
The purpose of the present study was to modulate the secretion of insulin and glucagon in Beagle dogs by stimulation of nerves innervating the intact and partly dysfunctional pancreas. Three 33-electrode spiral cuffs were implanted on the vagus, splanchnic and pancreatic nerves in each of two animals. Partial dysfunction of the pancreas was induced with alloxan. The nerves were stimulated using rectangular, charge-balanced, biphasic, and constant current pulses $(200 \mu \mathrm{s}, 1 \mathrm{~mA}$, $20 \mathrm{~Hz}$, with a $100-\mu$ s delay between biphasic phases). Blood samples from the femoral artery were drawn before the experiment, at the beginning of stimulation, after $5 \mathrm{~min}$ of stimulation, and $5 \mathrm{~min}$ after the end of stimulation. Radioimmunoassay data showed that in the intact pancreas stimulation of the vagal nerve increased insulin ( +99.2 $\mu \mathrm{U} / \mathrm{ml})$ and glucagon $(+18.7 \mathrm{pg} / \mathrm{ml})$ secretion and decreased C-peptide secretion $(-0.15 \mathrm{ng} / \mathrm{ml})$. Splanchnic nerve stimulation increased insulin $(+1.7 \mu \mathrm{U} / \mathrm{ml})$, C-peptide $(+0.01 \mathrm{ng} / \mathrm{ml})$, and glucagon $(+50 \mathrm{pg} /$ $\mathrm{ml})$ secretion, whereas pancreatic nerve stimulation did not cause a marked change in any of the three hormones. In the partly dysfunctional pancreas, vagus nerve stimulation increased insulin $(+15.5 \mu \mathrm{U} /$ $\mathrm{ml})$, glucagon $(+11 \mathrm{pg} / \mathrm{ml})$, and C-peptide $(+0.03 \mathrm{ng} / \mathrm{ml})$ secretion. Splanchnic nerve stimulation reduced insulin secretion $(-2.5 \mu \mathrm{U} / \mathrm{ml})$ and increased glucagon $(+58.7 \mathrm{pg} / \mathrm{ml})$ and C-peptide $(+0.39 \mathrm{ng} / \mathrm{ml})$ secretion, and pancreatic nerve stimulation increased insulin $(+0.2 \mu \mathrm{U} / \mathrm{ml})$, glucagon $(+5.2 \mathrm{pg} / \mathrm{ml})$, and C-peptide $(+0.08$ $\mathrm{ng} / \mathrm{ml}$ ) secretion. It was concluded that vagal nerve stimulation can significantly increase insulin secretion for a prolonged period of time in intact and in partly dysfunctional pancreas.
\end{abstract}

\section{Introduction}

Since the discovery of insulin in the early twenties $(1,2)$, research has been concentrated on the elucidation of the mechanisms that control hormone secretion by the pan-
Key words

- Functional electrical

stimulation

- Implanted electrodes

- Autonomic nerves

- Pancreatic secretion

- Insulin

- Glucagon creas. Most recent reviews have dealt with the myriad of chemical factors known to affect these hormones $(3,4)$, but only few have dealt with the possibilities opened by the method of functional electrical stimulation of peripheral nerves of the autonomic 
nervous system innervating the pancreas (57). A problem is how to elicit increased insulin secretion in patients with diabetes whose disease is not as severe as when islets of Langerhans are no longer functional. In the latter cases there is no way to cure diabetes other than to inject insulin. In severe diabetes treated by insulin injection, severe complications occur much earlier and more often than in normal individuals. Therefore, by using functional electrical stimulation as an alternative method we may slow down the progression of diabetes during a specific stage of the disease, and possibly eliminate the need for insulin. If functional electrical stimulation could be applied to nerves that innervate the pancreas, the lives of individuals with diabetes could be more normal, with a consequent reduction in the very high direct and indirect costs involved in the treatment of diabetes.

It is well known that stimulation of the autonomic nerves and treatment with neurotransmitters affect islet hormone secretion (8-12). Insulin secretion is stimulated by parasympathetic nerves or their neurotransmitters and inhibited by sympathetic nerves or their neurotransmitters $(13,14)$. Recently, several investigators have reported that stimulation of the vagus nerve increases insulin secretion in dogs and baboons. Moreover, stimulation of the splanchnic nerves causes morphological changes within the islets and the cells that are compatible with increased secretory activity. Accordingly, glucagon secretion is increased after stimulation of the splanchnic nerve in cats and calves (8) and after stimulation of the mixed pancreatic nerve in dogs (10). Ahrén et al. (15) and Ahrén and Taborsky Jr. (16) have studied the mechanisms of vagal nerve stimulation of glucagon and insulin secretion in halothane-anesthetized dogs. Both ventral and dorsal branches of the thoracic vagi were stimulated for $10 \mathrm{~min}$ using square wave impulses of 5-s duration and $13.5-\mathrm{mA}$ current intensity at a frequency of $10 \mathrm{~Hz}$ below the heart. The authors concluded that vagal nerve stimulation produces a moderate increase of glucagon secretion and a marked increase of insulin secretion in the dog. Furthermore, arterial glucose levels were increased. Woods and Porte Jr. (14) pointed out that most vertebrate species have a rich supply of autonomic neurons reaching the islets of Langerhans. These islets are richly innervated by parasympathetic, sympathetic, and sensory nerves. Both adrenergic and cholinergic fibers innervate all types of islet secretory cells, although there are species differences (17). Stimulation of the parasympathetic nervous system leads to insulin secretion, whether at the level of the lateral hypothalamic nuclei, the motor nuclei of the vagus, the vagal trunks, or the mixed pancreatic nerves. Stimulation of the sympathetic nervous system inhibits insulin secretion at the level of the ventromedial hypothalamic nuclei, the splanchnic nerves, or the mixed pancreatic nerves. The opposite responses occur for glucagon.

In the early experiments, insulin could not be measured directly, although many of the experiments provided compelling evidence. Experimenters inferred changes in insulin levels from changes of glucose levels that occurred after stimulation of the vagus. It was generally concluded that a fall in blood glucose observed in a few experimental animals reflected increased insulin secretion. Zunz and La Barre (2) showed that when the pancreatic blood of a large adrenalectomized dog was shunted into the vascular system of a smaller recipient dog, stimulation of the vagus of the larger dog resulted in pronounced hypoglycemia of the smaller one. They concluded that vagal stimulation leads to insulin secretion. These experiments, however, did not differentiate the direct effects of vagal stimulation of the islets from possible vagal stimulation of the secretion of hormones from the intestine, many of which can themselves elicit insulin secretion. Although gut hormones may facilitate the in- 
crease in insulin that follows vagal stimulation, they are unnecessary.

The working hypothesis of the present study was that with the stimulation of superficial regions of nerves innervating the mammalian pancreas it is possible to elicit increased secretion of glucagon, and especially insulin, at different ratios into the blood. The hypothesis was that, using chronically implanted multielectrode spiral cuffs, it would be possible to stimulate superficial regions of nerves innervating the pancreas of a dog and to elicit an increased secretion of hormones, especially insulin, in a dog with an incompletely dysfunctional pancreas. Thus, the purpose of the study was to modulate the secretion of insulin and glucagon into the blood of a healthy dog and a diabetic dog by stimulation of nerves innervating the pancreas.

\section{Material and Methods}

\section{Multielectrode spiral cuff}

A cuff was made by bonding together two 0.1-mm thick silicone sheets (18). Once the sheet was stretched and fixed in that position, it was covered with a layer of adhesive (MED-1511, NuSil, Carpinteria, CA, USA). A second unstretched sheet was placed on the adhesive and the composite was compressed to a thickness of $0.3 \mathrm{~mm}$. When released, the composite curled into a spiral tube as the stretched sheet contracted to its natural length. The diameter of the cuff was related to the amount of stretch: the greater the stretch, the smaller the diameter. Thirtythree 0.6-mm wide, $1.5-\mathrm{mm}$ long and 50- $\mu \mathrm{m}$ thick rectangular electrodes made of platinum ribbon (99.99\% purity) connected to lead wires (AS 631, Cooner Wire, Chatsworth, CA, USA) were then mounted on a third 0.1-mm thick silicone sheet. The electrodes were arranged in three parallel groups, each containing 11 electrodes spaced at a distance of $0.5 \mathrm{~mm}$. The distance between the spiral groups was $6 \mathrm{~mm}$. Each electrode marked with the same number within each of the three parallel spiral groups was in the same position. Accordingly, 11 groups of three electrodes were placed along the same line in a longitudinal direction. All electrodes of the central and outer groups were then connected to the corresponding lead wires. The silicone sheet with the arranged electrodes was then bonded to the inner side of the mechanically opened cuff. The length of the cuff was optimized so that the surface of the nerve covered by the spiral cuff would be as small as possible to prevent damage associated with blood supply and excessive mechanical trauma of the nerve. Therefore, the cuff with an inner diameter of $2.5 \mathrm{~mm}$ was trimmed to the length of $18 \mathrm{~mm}$ as shown in Figure 1.

Finally, all lead wires were connected to a special common connector to be implanted within the lateral subcutaneous tissue for the time between experimental sessions. This common connector was designed to enable both the simple mechanical and electrical connections to the switch module to be also used during the stimulating sessions. The

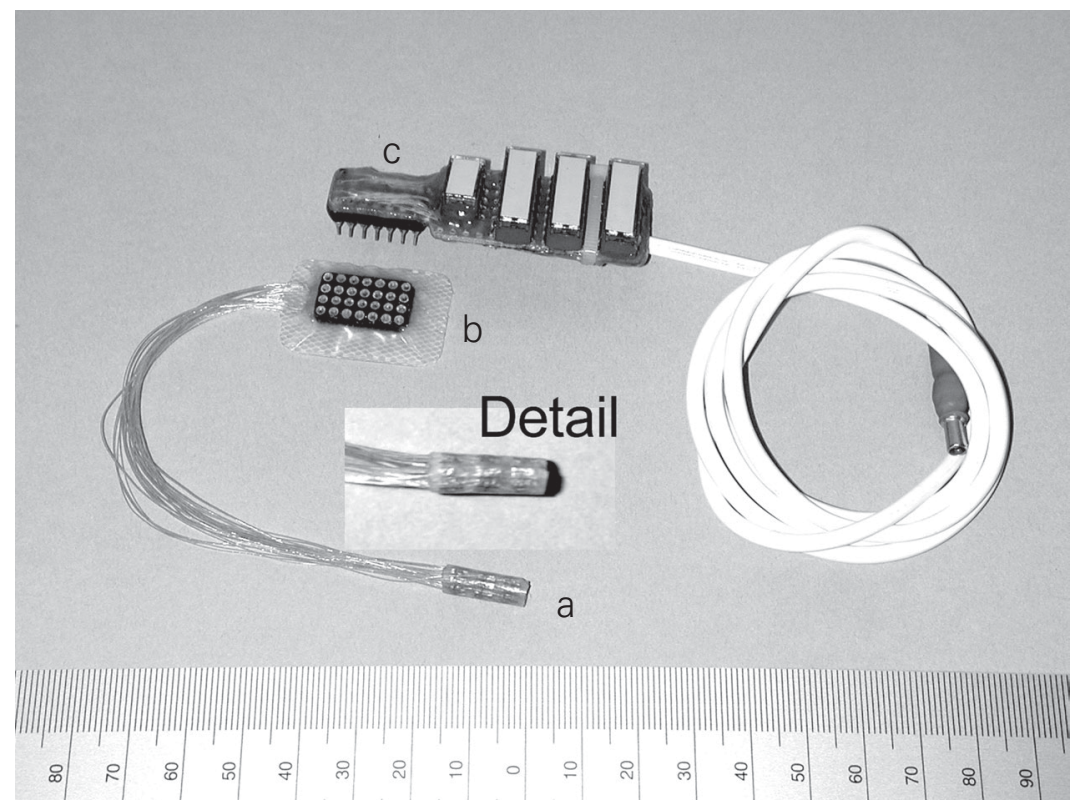

Figure 1. Cuff used for stimulation: a) 33-electrode spiral cuff, b) subcutaneous common connector, and c) switch module. 
common connector was also designed to permit simple and reliable multiple use. This is very important because the common connector must be reimplanted several times between individual experiments without any damage.

\section{Surgical implantation}

The study was performed on two Beagle dogs. Under fully sterile conditions, gassterilized cuffs were implanted according to

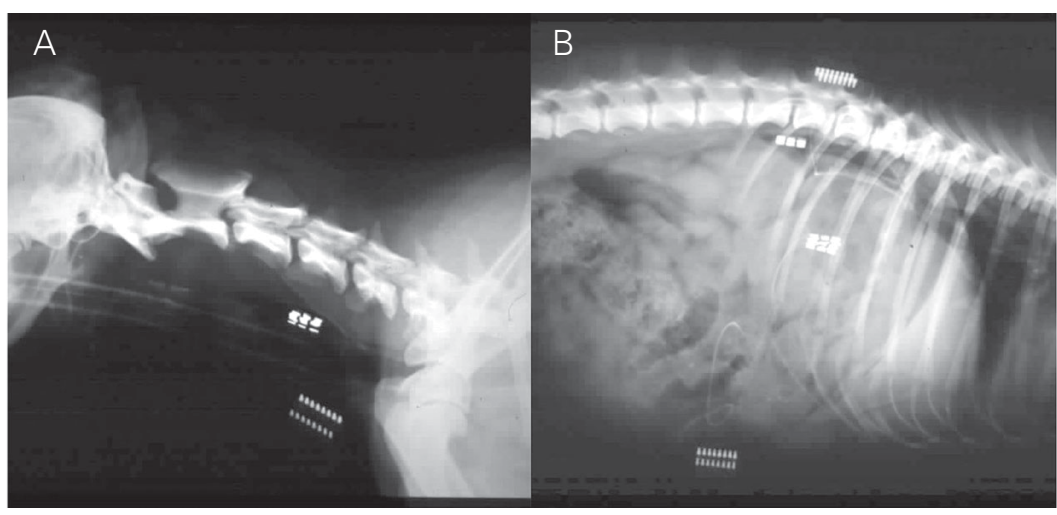

Figure 2. A, X-ray of the 33-electrode spiral cuff implanted on the vagus nerve; $B, X$-ray of the 33-electrode spiral cuffs implanted on the splanchnic (near the spine) and mixed pancreatic (below the spine) nerves of the dog.

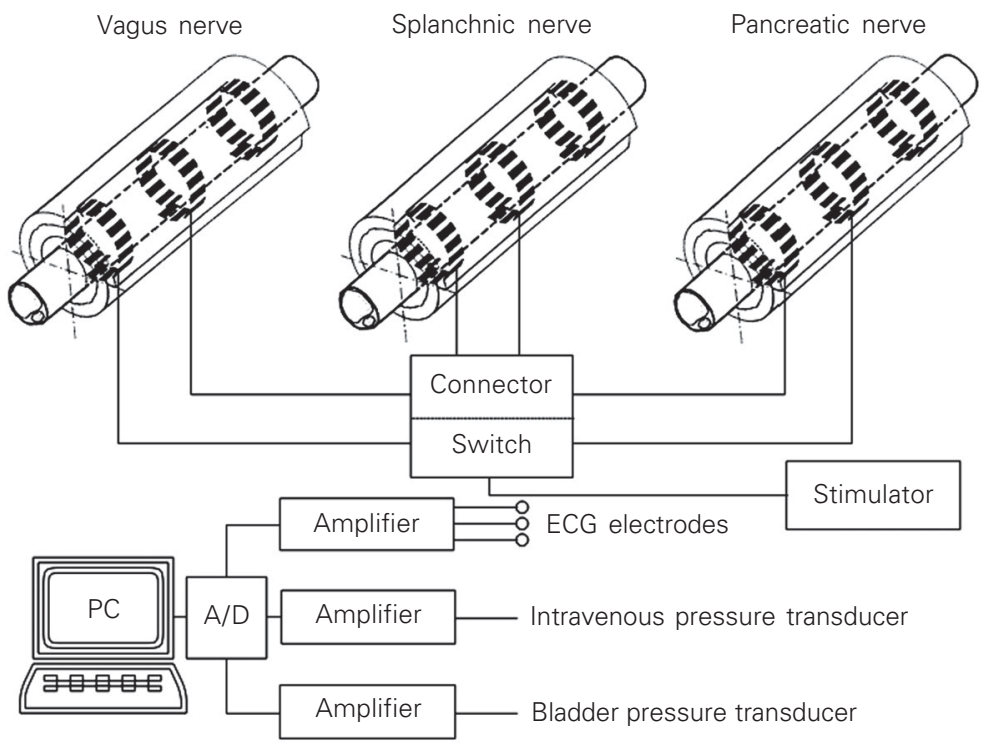

Figure 3. Schematic diagram illustrating an animal experiment in which the vagus, splanchnic and pancreatic nerves were stimulated. a protocol approved by the Ethics Committee of the Veterinary Faculty, Ljubljana, as described below. The animals were premedicated with $40 \mu \mathrm{g} / \mathrm{kg}$ medetomidine, im (Domitor; Orion Corp., Espoo, Finland) and $0.2 \mathrm{mg} / \mathrm{kg}$ methadone, sc (Heptanon; Pliva, Zagreb, Croatia). Induction was performed with 1.0 to $2.0 \mathrm{mg} / \mathrm{kg}$ propofol, iv (Diprivan; Zeneca Pharmaceuticals Ltd., Macclesfield, Chesire, UK) (19). General anesthesia was maintained with 0.8 to $1.5 \mathrm{vol} \%$ isoflurane (Forane; Abbott Laboratories Inc., Abbott Park, IL, USA) in $100 \% \mathrm{O}_{2}$. When necessary, analgesia was maintained during surgery with 0.5 to $2.0 \mathrm{mg} / \mathrm{kg}$ ketamine, iv (Ketamine; Veyx-Pharma GmbH, Schwarzenborn, Germany). Antibiotics (20 mg/kg cefazolin, iv; Cefamezin; Krka, Novo Mesto, Republic of Slovenia) were administered perioperatively. Room temperature was kept between $23.4^{\circ}$ and $24.4^{\circ} \mathrm{C}$, and the temperature of the skin of the neck was also continuously monitored. According to our model, the cuff to be implanted on the vagus nerve should be installed on the nerve trunk just before bifurcation into the dorsal and ventral branches. However, to avoid potentially fatal trauma, the cuff was installed on the vagus nerve at the level of the neck as shown in panel A of Figure 2. The cuff on the splanchnic nerve was installed on the nerve trunk before the celiac ganglion as shown in panel B of Figure 2. Here the installation was complicated due to a very limited space.

The cuff on the pancreatic nerve was installed at the site just before the nerve enters the pancreas, as also shown in panel B of Figure 2. The leads of the implanted cuffs were routed between other organs and under the skin to the three corresponding common connectors fixed under the skin. Finally, the incisions were closed and the animals awakened. Analgesia during the early recovery period was provided with 0.3 to $0.5 \mathrm{mg} / \mathrm{kg}$ methadone, $s c$, three times a day. Tramadol, $8.0 \mathrm{mg} / \mathrm{kg}, s c$ (Tramal; Grünenthal GmbH, Stolberg, Germany) was administered three 
times a day for two additional days. The first experiment was performed 30 days after implantation to allow the devices to stabilize.

\section{Electrical stimulation of whole nerves}

Stimulations of the intact pancreas were performed 2 (in the first dog) and 6 (in the second dog) months after implantation. The main purpose of these trials was to obtain data about normal levels of glucagon, insulin, and C-peptide in blood. However, stimulation of the pancreas, rendered partly dysfunctional with alloxan, was conducted in both dogs 10 months after implantation and 17 days after disablement with alloxan. The period of the first 10 days was estimated to be necessary for the partial destruction of islets of Langerhans to be completed $(20,21)$. When the subcutaneously implanted common connector belonging to one of the implanted cuffs was removed from the body, it was thoroughly cleaned and dried and then placed on the cleaned skin close to the wound. The common connector and the wound were then covered with self-adhesive surgical foil throughout the entire experiment. A special cable was developed to connect the common connector to the outlets of the stimulator. At one end of the cable to be connected to the common connector there was a switch module designed to fit its pins. The connection itself was made simply by perforating the self-adhesive surgical foil with the pins of the switch module and inserting them into the common connector. For the stimulations, it was of crucial importance that the connection would permit reliable mechanical and galvanic connections. Moreover, the common connector and the wound were insulated from the ambient atmosphere.

The 33-electrode spiral cuff also permits selective stimulation of the nerve fibers within the superficial regions close to the groups of the three electrodes. However, the aim of the present experiment was to stimulate all superficial regions close to the uncovered groups of three electrodes of the aforementioned three nerves, as shown in Figure 3.

Accordingly, the switches of the switching module belonging to the cable were turned on so as to connect all electrodes in the central spiral group together and to form a single spiral electrode composed of 11 platinum electrodes. Similarly, all electrodes in both outer spiral groups were connected together, forming two outer spiral electrodes, each consisting of 11 platinum electrodes. To obtain a "quasi-bipolar" stimulating configuration as described elsewhere (18), the two outer spiral electrodes were short-circuited. The previously short-circuited outer electrodes of each spiral cuff were then connected through an explanted connector and through the switch module to one end of a custom-designed electrical stimulator, while the corresponding central electrodes were connected to the other end.

In the experiments, each nerve was stimulated with biphasic rectangular current pulses with the following parameters: width, $200 \mu \mathrm{s}$, amplitude adjustable between 10 and $20 \mathrm{~mA}$, and frequency, $20 \mathrm{~Hz}$. ECG, blood pressure, and pressure in the bladder were constantly monitored to assess the effect of stimulation on the function of the cardiovascular system, lungs, and urinary tract.

\section{Alloxan administration}

To partly disable the pancreas, causing insulin-dependent diabetes mellitus or type I diabetes, the death of a certain portion of pancreatic islet $\beta$-cells was induced (20-22). For this purpose, alloxan (Sigma, St. Louis, MO, USA) was dissolved in physiological saline $(0.9 \% \mathrm{NaCl})$ at a concentration of $200 \mathrm{mg} / \mathrm{ml}$. A quantity of freshly prepared solution was then injected $i v$ at $50 \mathrm{mg} / \mathrm{kg}$. After 10 days the pancreas was partially disabled in an irreversible manner and permanent hyperglycemia was induced. Since 
the protocols for treating naturally or experimentally induced type I diabetes are the same, insulin (Homofan 100, Pliva) therapy was applied (1 IE/kg animal weight). To stabilize blood glucose at a level approximately four times higher than normal, a period of 7 days prior to the stimulation sessions was introduced. After the last experiment, both animals were sacrificed using the veterinary drug T61 (Hoechst, Frankfurt, Germany).

\section{Blood sampling and analysis}

Samples from the femoral artery were drawn before each experiment to obtain initial data about blood glucagon, insulin, and C-peptide levels. Blood was obtained from the femoral artery at the beginning of stimulation, after $5 \mathrm{~min}$ of stimulation, and $5 \mathrm{~min}$ after the end of stimulation. The samples were placed on ice and centrifuged at $4^{\circ} \mathrm{C}$ immediately after the end of the experiments, and plasma was separated and frozen at $-20^{\circ} \mathrm{C}$ until radioimmunoassay. Plasma glucose was measured by the glucose oxidase method and hematocrit was determined at regular intervals throughout the experiments.

Kits from Linco Research, Inc. (St. Charles, MO, USA) were used for radioimmunoassay of canine C-peptide, human insulin, and glucagon.

\section{Results}

Since the results obtained for the first and the second dog were quite similar, we present them as an average of the data obtained for both dogs. Stimulation of the vagus nerve caused a statistically significant increase in insulin secretion from 13 to $112.2 \mu \mathrm{U} / \mathrm{ml}$ (Table 1). However, vagal nerve stimulation did not cause significant changes in glucagon secretion (from 106.6 to $125.3 \mathrm{pg} / \mathrm{ml}$ ). Vagal nerve stimulation also decreased Cpeptide secretion from 0.49 to $0.34 \mathrm{ng} / \mathrm{ml}$. Splanchnic nerve stimulation of the intact pancreas did not cause marked changes in insulin secretion (from 17 to $18.7 \mu \mathrm{U} / \mathrm{ml}$, on average) but caused a considerable increase in glucagon secretion from 125.3 to 175.3 $\mathrm{pg} / \mathrm{ml}$. Splanchnic nerve stimulation did not cause marked changes in C-peptide secretion (from 0.48 to $0.49 \mathrm{ng} / \mathrm{ml}$, on average). Pancreatic nerve stimulation in the intact pancreas did not cause significant changes in the secretion of any of the three hormones.

Vagal nerve stimulation of the dogs with partly dysfunctional pancreas caused an increase in insulin secretion from 12.6 to 28.1 $\mu \mathrm{U} / \mathrm{ml}$, as well as an increase in glucagon secretion from 119.3 to $130.3 \mathrm{pg} / \mathrm{ml}$ and a minor increase in C-peptide secretion from 0.55 to $0.58 \mathrm{ng} / 1$ (Table 2). Splanchnic nerve stimulation in the severed pancreas caused a minor decrease in insulin secretion from

Table 1. Effect of nerve stimulation on pancreatic hormones in the blood of the second dog with intact pancreas.

\begin{tabular}{|c|c|c|c|c|c|c|c|c|c|c|c|c|}
\hline \multirow[t]{3}{*}{ Stimulated nerve } & \multicolumn{12}{|c|}{ Hormone levels in blood after rest periods ( $\mathrm{min}$ ) between 60-s stimulation sessions } \\
\hline & \multicolumn{3}{|c|}{$0 \mathrm{~min}$} & \multicolumn{3}{|c|}{$15 \mathrm{~min}$} & \multicolumn{3}{|c|}{$10 \mathrm{~min}$} & \multicolumn{3}{|c|}{$8 \mathrm{~min}$} \\
\hline & $\begin{array}{c}\text { INS } \\
(\mu \mathrm{U} / \mathrm{ml})\end{array}$ & $\begin{array}{c}\mathrm{GLU} \\
(\mathrm{pg} / \mathrm{ml})\end{array}$ & $\begin{array}{c}\text { C-P } \\
\text { (ng/ml) }\end{array}$ & $\begin{array}{c}\text { INS } \\
(\mu \mathrm{U} / \mathrm{ml})\end{array}$ & $\begin{array}{c}\mathrm{GLU} \\
(\mathrm{pg} / \mathrm{ml})\end{array}$ & $\begin{array}{c}\text { C-P } \\
(\mathrm{ng} / \mathrm{ml})\end{array}$ & $\begin{array}{c}\text { INS } \\
(\mu \mathrm{U} / \mathrm{ml})\end{array}$ & $\begin{array}{c}\mathrm{GLU} \\
\text { (pg/ml) }\end{array}$ & $\begin{array}{c}\text { C-P } \\
\text { (ng/ml) }\end{array}$ & $\begin{array}{c}\text { INS } \\
(\mu \mathrm{U} / \mathrm{ml})\end{array}$ & $\begin{array}{c}\mathrm{GLU} \\
(\mathrm{pg} / \mathrm{ml})\end{array}$ & $\begin{array}{c}\text { C-P } \\
(\mathrm{ng} / \mathrm{ml})\end{array}$ \\
\hline Vagus & 13 & 106.6 & 0.49 & 112.2 & 125.3 & 0.34 & - & - & - & - & - & - \\
\hline Splanchnic & 17 & 125.3 & 0.48 & - & - & - & 18.7 & 175.3 & 0.49 & - & - & - \\
\hline Pancreatic & 15.7 & 122.2 & 0.3 & - & - & - & - & - & - & 16.6 & 125.6 & 0.25 \\
\hline
\end{tabular}

The basal content of hormones in blood 50 min before stimulation was: insulin (INS), $25.3 \mu \mathrm{U} / \mathrm{ml}$; glucagon (GLU), $123.7 \mathrm{pg} / \mathrm{ml}$; C-peptide (C-P), $0.74 \mathrm{ng} / \mathrm{ml}$. 
15.8 to $13.3 \mu \mathrm{U} / \mathrm{ml}$ and a considerable increase in glucagon secretion from 74.4 to $133.1 \mathrm{pg} / \mathrm{m}$, as well as a small increase in Cpeptide secretion from 0.29 to $0.68 \mathrm{ng} / \mathrm{ml}$. Pancreatic nerve stimulation in the severed pancreas did not cause marked changes in insulin secretion (from 6.7 to $6.9 \mu \mathrm{U} / \mathrm{ml}$ ) but caused a minor increase in glucagon and $\mathrm{C}$ peptide secretion (from 90.9 to $96.1 \mathrm{pg} / \mathrm{ml}$ for glucagon and from 0.49 to $0.57 \mathrm{ng} / \mathrm{ml}$ for C-peptide).

In series of stimulations in which the current pulses ranged from 10 to $20 \mathrm{~mA}$, measurable changes were observed in the splanchnic and vagus nerves. Splanchnic nerve stimulation with a current of $12 \mathrm{~mA}$ or more increased bladder pressure from 8 to $12.5 \mathrm{mmHg}$ and precipitated generalized stomach contractions. Dramatic changes were observed during stimulation of the vagus nerve with a current of more than $18 \mathrm{~mA}$. There was a rapid decrease of arterial blood pressure from 92 to $61 \mathrm{mmHg}$ and an irregular heart beat. A further increase of the vagal stimuli caused brachycardia, followed by asystolia and hypotension.

\section{Discussion}

The present study has demonstrated for the first time that multielectrode spiral cuffs chronically implanted on the nerves innervating the pancreas of a dog can elicit increased glucagon and insulin secretion from an intact or an incompletely dysfunctional pancreas.

The cuffs act on the nerve with a defined and constant pressure and permit monopolar and bipolar stimulation of the whole nerve as well as selective monopolar and bipolar stimulation of different superficial regions of the nerve with many combinations possible. The results of this study could be used in various types of animal and basic human studies of the neurophysiology of endocrine glands. Ultimately, the spiral cuffs could be used for both stimulation and recording. The present study has provided new information about the electrophysiology of the pancreas and the regulation of both insulin and glucagon secretion. Recent studies have dealt with chemical and electrostimulating factors known to affect these hormones $(8,10,15,16)$, but none has dealt with factors resulting in stimulation of the vagus, splanchnic, and mixed pancreatic nerves with multielectrode cuffs implanted for a prolonged period of time. The present study also contributed to the development of new implantable systems for the stimulation of peripheral nerves in the autonomic nervous system, glands, and other organs innervated by the autonomic nervous system, as well as electrode systems and sensors for recording different biological signals.

It is well known that cardiovascular disease is the leading cause of death in diabetes mellitus. Atherosclerosis, arteriosclerosis, and severe heart disease as a consequence of damaged coronary vessels appear much earlier in diabetics than in healthy individuals. By using a method of electrical stimulation of the pancreatic nerves it should be possible to slow down the progress of these diseases. In addition, with electrical stimulation, the doses of insulin could be reduced, and in cases in which islets of Langerhans still function but do not secrete enough insulin, insulin treatment could even be abolished. A

Table 2. Effect of nerve stimulation on pancreatic hormones in blood of the second dog with partly dysfunctional pancreas.

\begin{tabular}{|c|c|c|c|c|c|c|}
\hline \multirow[t]{3}{*}{ Stimulated nerve } & \multicolumn{6}{|c|}{$\begin{array}{l}\text { Hormone levels in blood after rest periods (min) } \\
\text { between } 60 \text {-s stimulation sessions }\end{array}$} \\
\hline & \multicolumn{3}{|c|}{$0 \mathrm{~min}$} & \multicolumn{3}{|c|}{$60 \mathrm{~min}$} \\
\hline & $\begin{array}{l}\text { INS } \\
(\mu \mathrm{U} / \mathrm{ml})\end{array}$ & $\begin{array}{l}\text { GLU } \\
(p g / m l)\end{array}$ & $\begin{array}{c}\mathrm{C}-\mathrm{P} \\
(\mathrm{ng} / \mathrm{ml})\end{array}$ & $\begin{array}{l}\text { INS } \\
(\mu \mathrm{U} / \mathrm{ml})\end{array}$ & $\begin{array}{c}\mathrm{GLU} \\
(\mathrm{pg} / \mathrm{ml})\end{array}$ & $\begin{array}{c}\text { C-P } \\
(\mathrm{ng} / \mathrm{ml})\end{array}$ \\
\hline Vagus & 12.6 & 119.3 & 0.55 & 28.1 & 130.3 & 0.58 \\
\hline Splanchnic & 15.8 & 74.4 & 0.29 & 13.3 & 133.1 & 0.68 \\
\hline Pancreatic & 6.7 & 90.9 & 0.49 & 6.9 & 96.1 & 0.57 \\
\hline
\end{tabular}

The basal content of hormones in blood 40 min before stimulation was: insulin (INS), $13.9 \mu \mathrm{U} / \mathrm{ml}$; glucagon (GLU), $150.8 \mathrm{pg} / \mathrm{ml}$; C-peptide (C-P), $0.85 \mathrm{ng} / \mathrm{ml}$. 
methodology as well as accompanying technological solutions could be developed and used to transfer this animal model to an alternative human model for the treatment of diabetes mellitus. However, a requirement for the potentially successful transfer of this model to man is a good functional result demonstrated by increased and reliable insulin secretion over a prolonged period of time. Moreover, a methodology involving spiral cuffs could be successfully used in the transfer to humans of this animal model of vagal nerve stimulation. Since the vagus nerve connects the brain to the internal organs, including the heart and digestive tract, a wide-range of vagal nerve stimulation applications should be possible.
However, the technique used to stimulate the autonomic nerves has extensive systemic effects, such as changes in endocrine function of many internal organs and glands, and even a nonspecific stress condition. Therefore, all possible systemic effects must be considered before this technique can be transferred to humans. One possible solution to reduce or even abolish these effects could be the technique of selective stimulation of autonomic nerves. One application under study is the use of vagal nerve stimulation in slowing the progress of coronary artery disease. Another potential application is the control of Parkinsonian and essential tremor.

\section{References}

1. Banting FG \& Gairns S (1924). Factors influencing the production of insulin. American Journal of Physiology, 68: 24-39.

2. Zunz E \& La Barre J (1928). Influence de I'hyperglycémie et de I'hypoglycémie des centres nerveux supérieus sur la sécrétion interne du pancreas. Annals of Physiology, 4: 688-693.

3. Ahrén B (2000). Autonomic regulation of islet hormone secretion implications for health and disease. Diabetologia, 43: 393-410.

4. Ahrén B (1999). Regulation of insulin secretion by nerves and neuropeptides. Annals of the Academy of Medicine, Singapore, 28: 99104.

5. Berthoud H-R \& Powley TL (1991). Morphology and distribution of efferent vagal innervation of rat pancreas as revealed with anterograde transport of Dil. Brain Research, 553: 336-341.

6. Love JA \& Szebeni K (1999). Morphology and histochemistry of the rabbit pancreatic innervation. Pancreas, 18: 53-64.

7. Love JA \& Szebeni K (1999). Histochemistry and electrophysiology of adult rabbit pancreatic neurons in primary culture. Pancreas, 18: 65-74.

8. Ahrén B, Veith RC \& Taborsky Jr GJ (1987). Sympathetic nerve stimulation versus pancreatic norepinephrine infusion in the dog: 1. Effects on basal release of insulin and glucagon. Endocrinology, 121: 323-331.

9. Dunning BE, Ahrén B, Veith RC \& Taborsky Jr GJ (1988). Nonadrenergic sympathetic neural influences on basal pancreatic hormone secretion. American Journal of Physiology, 255: E785-E792.

10. Dunning BE \& Taborsky Jr GJ (1989). Galanin release during pancreatic nerve stimulation is sufficient to influence islet function. American Journal of Physiology, 256 (Part 1): E191-E198.

11. Love JA, Richards NR, Owyang C \& Dawson DC (1998). Muscarinic modulation of voltage-dependent calcium channels in insulin-secreting HIT-T15 cells. American Journal of Physiology, 274: G397G405.
12. Roy MW, Le KC, Jones MS \& Miller RE (1984). Neural control of pancreatic insulin and somatostatin secretion. Endocrinology, 115: 770-775.

13. Sha L, Love JA, Ma R \& Szurszewski JH (1997). Cholinergic transmission in pancreatic ganglia of the cat. Pancreas, 14: 83-93.

14. Woods SC \& Porte Jr D (1987). Neural control of the endocrine pancreas. Physiological Reviews, 54: 596-619.

15. Ahrén B, Paquette TL \& Taborsky Jr GJ (1986). Effect and mechanism of vagal nerve stimulation on somatostatin secretion in dogs. American Journal of Physiology, 250: E212-E217.

16. Ahrén B \& Taborsky Jr GJ (1986). The mechanism of vagal nerve stimulation of glucagon and insulin secretion in the dog. Endocrinology, 118: 1551-1557.

17. King BF, Love JA \& Szurszewski JH (1989). Intracellular recordings from pancreatic ganglia of the cat. Journal of Physiology, 419: 379403.

18. Rozman J, Zorko B \& Bunc M (1999). Stimulation of pancreatic nerves of a dog. In: Poster Abstracts. National Institute of Neurological Disorders and Stroke, Bethesda, MD, USA, 3.

19. Havel PJ, Paquette TL \& Taborsky Jr GJ (1986). Halothane is less suppressive than pentobarbital on reflex and neural activation of pancreatic F-cells. American Journal of Physiology, 251 (Part 1): E111-E116.

20. Ahrén B \& Sundkvist G (1995). Long-term effects of alloxan in mice. International Journal of Pancreatology, 17: 197-201.

21. Herson PS \& Ashford MLJ (1997). Activation of a novel non-selective cation channel by alloxan and $\mathrm{H}_{2} \mathrm{O}_{2}$ in the rat insulin-secreting cell line CRI-G1. Journal of Physiology, 501: 59-66.

22. Tyrberg B, Eizirik DL, Marklund SL, Olejnicka B, Madsen OD \& Andersson A (1999). Human islets in mixed islet grafts protect mouse pancreatic beta-cells from alloxan toxicity. Journal of Pharmacological and Toxicological Methods, 85: 269-275. 